\title{
Human insulin receptor substrate-1 gene (IRS1): chromosomal localization to 2 q35-q36.1 and identification of a simple tandem repeat DNA polymorphism
}

\author{
M. Stoffel ${ }^{1}$, R.Espinosa III ${ }^{2}$, S. R. Keller ${ }^{3}$, G. E.Lienhard ${ }^{3}$, M. M. Le Beau ${ }^{2}$ and G.I Bell $^{1}$ \\ ${ }^{1}$ Howard Hughes Medical Institute, Departments of Biochemistry and Molecular Biology, Chicago, Illinois, USA \\ ${ }^{2}$ Department of Medicine, University of Chicago, Chicago, Illinois, USA \\ ${ }^{3}$ Department of Biochemistry, Dartmouth Medical School, Hanover, New Hampshire, USA
}

\begin{abstract}
Summary. The protein designated as insulin receptor substrate-1 (IRS-1) is a major substrate for the insulin receptor tyrosine kinase. Since post-receptor defects in the insulin signalling pathway are a common feature of Type 2 (noninsulin-dependent) diabetes mellitus, we have cloned the human IRS-1 gene in order to study the role of genetic variation in this gene in the pathogenesis of diabetes mellitus. As
\end{abstract}

a first step in these studies, we have mapped the IRS-1 gene to chromosome 2, bands q35- q36.1 and identified a simple tandem repeat DNA polymorphism in this gene that will be useful for genetic studies.

Key words: DNA polymorphism, genetics, chromosome 2 .
Insulin resistance and beta-cell malfunction account for the complex clinical presentation of Type 2 (non-insulindependent) diabetes mellitus [1]. Candidate sites for genetic defects of insulin resistance include the insulin receptor, its signal transduction pathway, and insulin-regulated genes involved in peripheral utilization of glucose or hepatic glucose production. Mutations in the insulin receptor have been identified in patients with syndromes of severe insulin resistance [2]; however, they are rare in patients with Type 2 diabetes. Similarly, rare variants of the GLUT4/muscle-adipocyte glucose transporter have been identified but they are not known to impair the function of this protein $[3,4]$.

Recently, several groups reported the isolation of cDNAs encoding a $160-185 \mathrm{kDa}$ phosphotyrosyl protein that is a substrate of the insulin receptor tyrosine kinase and a putative participant in insulin signalling [5] (S.R.Keller, R. Aebersold, C.W.Garner and G.E.Lienhard, unpublished observations). This protein, designated as insulin receptor substrate 1 or IRS-1, is found in a variety of insulin responsive cells and tissues. It exhibits no intrinsic enzymatic activity but is believed to serve as a docking protein involved in binding and activating other signal transduction molecules after being phosphorylated on tyrosine by the insulin receptor kinase. Because of its central role in the signal transduction pathway, IRS-1 is a candidate for the site of the defect in insulin action seen in patients with Type 2 diabetes.

As a first step in studying the role of genetic variation in IRS- 1 in the aetiology of Type 2 diabetes, we have cloned the human IRS-1 gene (IRS1), determined its chromosomal localization and identified a highly polymorphic simple tandem repeat DNA polymorphism in this gene that will be useful for genetic studies.

\section{Materials and methods}

\section{General methods}

Standard methods were carried out as described in Sambrook et al. [6]. DNA sequencing was done by the dideoxynucleotide chain termination procedure after subcloning appropriate DNA fragments into M13 mp18 or M13 mp19. The sequence was confirmed on both strands.

\section{Isolation of the human IRS-1 gene}

A human male placenta genomic library in $\lambda$ FIX II (Stratagene, LaJolia, Calif., USA; catalogue no. 946203) was screened by hybridization with a ${ }^{32} \mathrm{P}$-labelled fragment of the mouse pp160, IRS-1, cDNA corresponding to nucleotides 594-1562 of the mouse cDNA sequence (S.R.Keller, R.Aebersold, C.W.Garner and G.E.Lienhard, unpublished observations). Five clones were obtained and designated $\lambda$ hIRS $1-1$ to -5 .

Chromosomal mapping using a human-hamster somatic cell hybrid panel

The chromosomal localization of IRS1 was determined using PCRable DNA from a somatic cell hybrid mapping panel (Bios, New Haven, Conn., USA) and the polymerase chain reaction (PCR) 

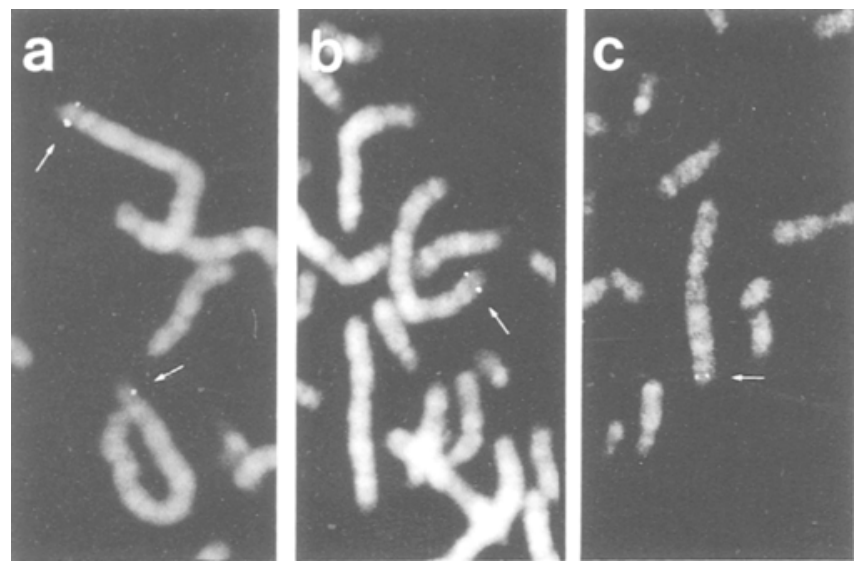

Fig. 1a-c. In situ hybridization of digoxigenin-labelled $\lambda$ hIRS1-4 DNA to human metaphase chromosomes from phytohaemagglutinin-stimulated peripheral blood lymphocytes. a-c, Partial metaphase spreads; the chromosome 2 homologues are identified with arrows. Specific labelling was observed at 2 q35-q36.1. Images were obtained using a Zeiss Axioplan microscope coupled to a thermoelectrically cooled charge coupled device camera. Separate images of DAPI-stained chromosomes and the hybridization were acquired and merged using image analysis software (IPLab Spectrum and GeneJoin)

with oligonucleotide primers IRS1-2, 5'-GTTCATTAATATTGTTCAACTGTGG-3', and IRS1-3, 5'-AATTAATTTGAAACCCGTTTGATGG-3'.

\section{Fluorescence in situ chromosomal hybridization}

Human metaphase cells were prepared from phytohaemagglutininstimulated peripheral blood lymphocytes. Fluorescence in situ bybridization was performed as described previously [7] using the clone $\lambda$ hIRS1 -4 which has an insert of 12.5 kilobase pairs (kb). Probes were prepared by nick-translation using Biotin-11-dUTP (Enzo Diagnostics, New York, NY, USA) or digoxigenin-11-dUTP (Boehringer Mannheim, Indianapolis, Ind., USA). Hybridization with biotin- labelled probes was detected with fluorescein-conjugated avidin (Vector Laboratories, Burlingame, Calif., USA) and digoxigenin-labelled probes were detected by incubation with rhodamine-conjugated sheep anti-digoxigenin antibodies (Boehringer Mannheim). Chromosomes were identified by staining with 4,6diamidino-2-phenylindole-dihydrochloride (DAPI).

\section{Identification of simple tandem repeat DNA polymorphism}

One microgramme of DNA from the five IRSI genomic clones was digested with Sau $3 \mathrm{AI}$ and after electrophoresis blotted onto a nitrocellulose filter and hybridized with ${ }^{32} \mathrm{P}$-labelled poly (dA- dC)-poly (dG-dT) (Pharmacia LKB Biotechnology, Piscataway, NJ, USA) as described previously [8]. A $1 \mathrm{~kb}$ fragment of $\lambda$ hIRS1-4 showed a strong hybridization signal. This fragment was isolated, subcloned into the BamHI site of M13 mp18 and sequenced.

\section{Amplification of the simple tandem repeat DNA polymorphism}

Two primers flanking the GT repeat-rich region identified in 2 HIRS1-4, IRS1-2 and IRS1-3, were selected by inspection and used to amplify the $\approx 138$ base pair region containing this repetitive sequence. The PCR was performed using ${ }^{32} \mathrm{P}$-labelled IRS1-2 and unlabelled IRS1-3. DNA was denatured at $94^{\circ} \mathrm{C}$ for $5 \mathrm{~min}$, followed by 30 cycles of denaturation at $94^{\circ} \mathrm{C}$ for $1 \mathrm{~min}$, annealing at $60^{\circ} \mathrm{C}$ for $30 \mathrm{~s}$, extension at $72^{\circ} \mathrm{C}$ for $90 \mathrm{~s}$ and a final extension step of $10 \mathrm{~min}$. The PCR products were analysed on a $5 \%$ denaturing polyacrylamide gel. The PCR reactions were carried out in a volume of $25 \mu \mathrm{l}$ containing $50 \mathrm{mmol} / 1 \mathrm{KCl}, 10 \mathrm{mmol} / \mathrm{l}$ Tris- $\mathrm{HCl} \mathrm{pH} 8.3,1.5 \mathrm{mmol} / \mathrm{l}$ $\mathrm{MgCl}_{2}, 200 \mu \mathrm{mol} / \mathrm{l}$ each of dATP, dCTP, dGTP, dTTP $0.1 \mu \mathrm{g}$ of DNA, 10 pmoles of each primer and 1.5 units of Taq polymerase (Perkin Elmer Cetus, Norwalk, Conn., USA) in a GeneAmp 9600 PCR System (Perkin Elmer Cetus).

\section{Results}

\section{Localization of the human IRS-1 gene}

To localize IRSI, we analysed the segregation of the human gene in DNA samples prepared from a panel of human-hamster somatic cell hybrids retaining different human chromosomes by PCR using primers IRS1-2 and IRS1-3. These studies indicated that IRS1 was on human chromosome 2 (data not shown). We confirmed this assignment and obtained a regional localization of IRSI by fluorescence in situ hybridization of biotin and digoxigenin-labelled $\lambda$ hIRS1-4 DNA to normal human metaphase chromosomes. Hybridization of $\lambda$ hIRS1-4 DNA resulted in specific labelling only of chromosome 2 (Fig. 1). In an analysis of 25 cells, specific labelling of 2 q35-q36.1 was observed on four ( 20 cells), three ( 4 cells), two ( 1 cell) and one ( 0 cells) chromatids of the chromosome 2 homologues. Similar results were obtained in three additional experiments using these probes. Thus, IRS1 is localized to chromosiome 2, bands q35-q36.1.

\section{Characterization of a simple tandem repeat DNA polymorphism}

The human IRS-1 genomic clones were screened for the presence of simple tandem repeat DNA polymorphisms (STRP) such as (GT) ${ }_{n}$ by hybridization with ${ }^{32} \mathrm{P}$-labelled poly $(\mathrm{dA}-\mathrm{dC})$-poly $(\mathrm{dG}-\mathrm{dT})$. One such sequence of the form (GT) ${ }_{11}$ CTGTGCAT(GT) ${ }_{12}$ was identified in $\lambda$ hIRS1-4 (Fig. 2). Oligonucleotide primers flanking this repeat element were selected (Fig. 2) and used to amplify this sequence in unrelated individuals of Caucasian, African-American and Japanese origin. This sequence was polymorphic (Fig. 2) and five alleles were observed in Caucasians and African-Americans, whereas four were noted in a smaller sample of unrelated Japanese subjects (Table 1). The heterozygosity (i.e. the fraction of individuals in whom the two alleles at this locus differed in size) varied from 0.53 to 0.75 indicating that this STRP will be very useful for linkage studies. Co-dominant inheritance of this STRP was demonstrated in two large families.

\section{Discussion}

We have mapped the human IRS1 gene to chromosome 2, bands q35-q36.1. In addition, we have identified a highly informative STRP that will facilitate genetic studies of IRS1 in diabetes-prone families especially those with the late-onset Type 2 diabetes in which insulin-resistance is a feature. 


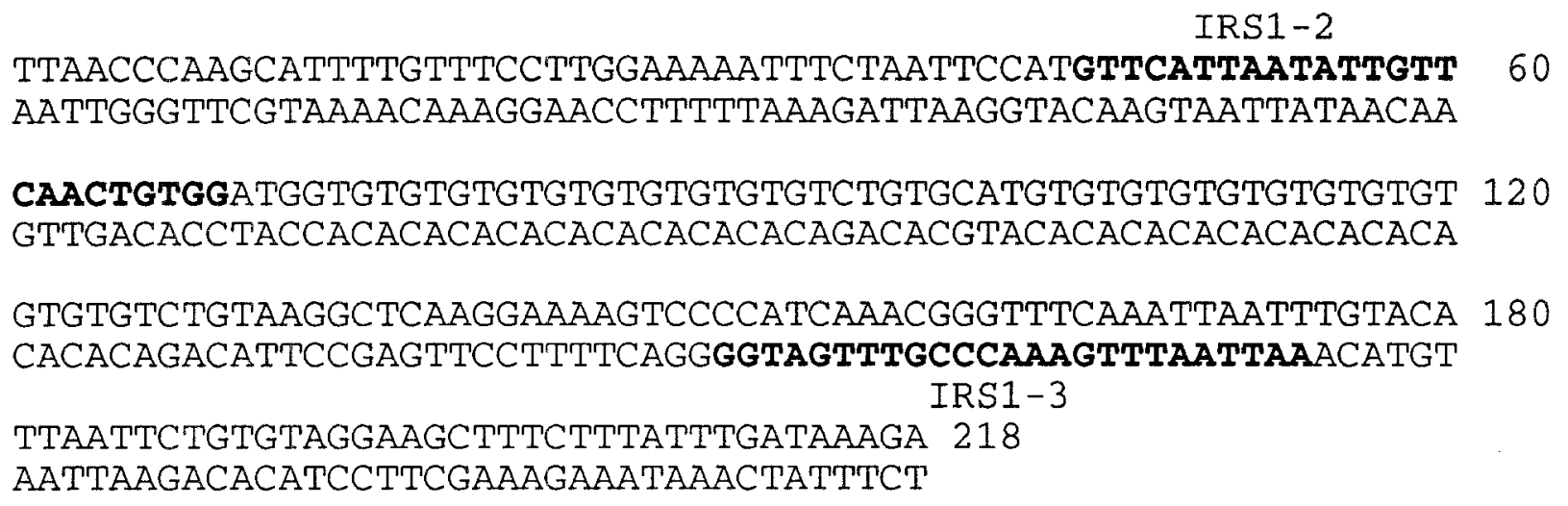

GTGTGTCTGTAAGGCTCAAGGAAAAGTCCCCATCAAACGGGTTTCAAATTAATTTGTACA 180 CACACAGACATTCCGAGTTCCTTTTCAGGGGTAGTTTGCCCAAAGTTTAATTAAACATGT

IRS $1-3$

TTAATTCTGTGTAGGAAGCTTTCTTTATTTGATAAAGA 218

AATTAAGACACATCCTTCGAAAGAAATAAACTATTTCT

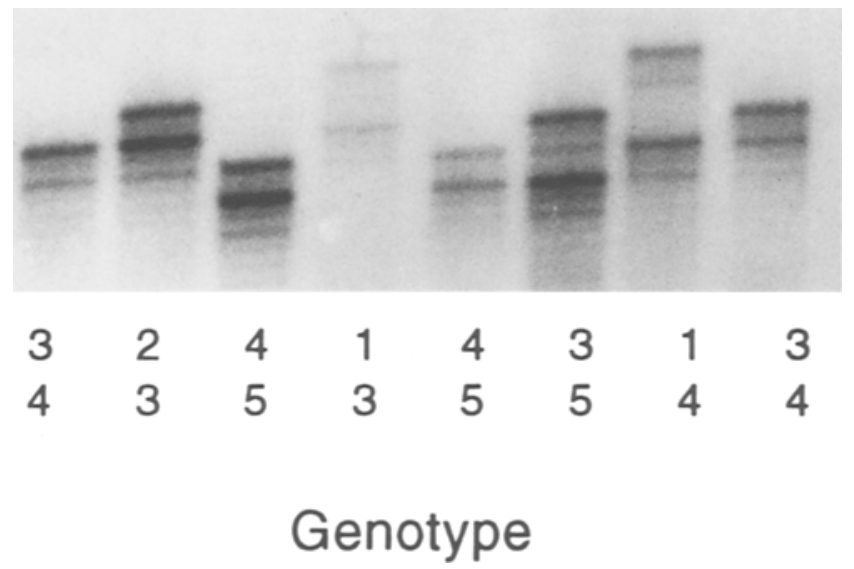

Table 1. Characterization of simple tandem repeat DNA polymorphism in the insulin receptor substrate-1 gene

\begin{tabular}{lllll}
\hline & & \multicolumn{3}{c}{ Racial Group } \\
\cline { 3 - 5 } & & Caucasian & $\begin{array}{l}\text { African- } \\
\text { American }\end{array}$ & Japanese \\
\hline \multicolumn{2}{l}{ Allele Frequencies } & $(n=28)$ & $(n=30)$ & $(n=20)$ \\
Allele & Size (bp) & & & \\
1 & 142 & 0.054 & 0.033 & - \\
2 & 140 & 0.018 & 0.350 & 0.025 \\
3 & 138 & 0.357 & 0.350 & 0.50 \\
4 & 136 & 0.482 & 0.217 & 0.450 \\
5 & 134 & 0.089 & 0.050 & 0.025 \\
Heterozygosity & 0.67 & 0.53 & 0.75 \\
\hline
\end{tabular}

bp, base pairs

Acknowledgements. We thank Mr. A. A. Fernald for technical assistance. These studies were supported by the Howard Hughes Medical Institute and PHS Grants DK-20595 (to the Diabetes Research and Training Center of The University of Chicago), CA-40046 (to M.M.L.) and DK-42816 (to G.E.L.). M.M.L. is a Scholar of the Leukemia Society of America. M.S. and S.R.K. were supported by fellowships from the Deutsche Forschungsgemeinschaft and Juvenile Diabetes Foundation International, respectively.

\section{References}

1. DeFronzo RA, Bonadonna RC, Ferrannini E (1992) Pathogenesis of NIDDM: a balancedoverview. Diabetes Care 15:318-368

2. Taylor SI, Cama A, Accili C et al. (1991) Genetic basis of endocrine disease. 1. Molecular genetics of insulin resistant diabetes mellitus. J Clin Endo Metab 73: 1158-1163
Fig. 2. Simple tandem repeat DNA polymorphism in human insulin receptor substrate-1 gene. Upper panel: Nucleotide sequence of the polymorphic region. The sequences of the primers used to amplify this region are shown in bold-face type. Lower panel: Polymerase chain reaction amplification of simple tandem repeat DNA polymorphism. The genotypes of the unrelated individuals studied here are shown at the bottom of the figure. The DNA sequence shown in this figure has been deposited in the GenBank data base with accession number L05198

3. Kusari J, Verma US, Buse JB, Henry RR, Olefsky JM (1991) Analysis of the gene sequences of the insulin receptor and the insulinsensitive glucose transporter (GLUT4) in patients with commontype non-insulin-dependent diabetes mellitus. J Clin Invest 88; $1323-1330$

4. Choi W-H, ORahilly S, Buse JB et al. (1991) Molecular scanning of insulin-responsive glucose transporter (GLUT4) gene in NIDDM subjects. Diabetes 40: 1712-1718

5. Sun XJ, Rothenberg P, Kahn CR et al. (1991) Structure of the insulin receptor substrate IRS-1 defines a unique signal transduction protein. Nature 352: 73-77

6. Sambrook J, Fritsch EF, Maniatis T (1989) Molecular cloning, a laboratory manual, 2 nd Ed., Cold Spring Harbor Laboratory Press, Cold Spring Harbor, NY

7. Rowley JD, Diaz MO, Espinosa R et al. (1990) Mapping chromosome band 11 q23 in human acute leukemia with biotinylated probes: identification of $11 \mathrm{q} 23$ translocation breakpoints with a yeast artificial chromosome. Proc Natl Acad Sci USA 87: 9358 9362

8. Nishi S, Stoffel M, Xiang K, Shows TB, Bell GI, Takeda J (1992) Human pancreatic beta-cell glucokinase: cDNA sequence and localization of the polymorphic gene to chromosome 7, band $\mathrm{p} 13$. Diabetologia 35: 743-747

Received: 16 September 1992

and in revised form: 26 November 1992

Dr. G. Bell

Howard Hughes Medical Institute

University of Chicago

5841 S. Maryland Ave., MC1028

Chicago, IL 60637

USA 